\title{
A Very Low Resistance, Non-Sintered Contact System for Use on Indium Phosphide Concentrator/Shallow Junction Solar Cells
}

Victor G. Weizer

National Aeronautics and Space Administration

Lewis Research Center

Cleveland, Ohio

and

Navid S. Fatemi

Sverdrup Technology, Inc.

Lewis Research Center Group

Brook Park, Ohio

Prepared for the

22nd Photovoltaic Specialists Conference

sponsored by the Institute of Electrical and Electronics Engineers

Las Vegas, Nevada, October 7-11, 1991

\section{N/SN}

(NASA-TM-105279) A VERY LOA RESISTANCE, NDN-SI VTEREO CONTACT SYSTEM FOR USE ON

INOIUM PHOSPHIDE CONCENTRATOR/SHALLOW

JUNCTIUN SULAR CELLS (VASA) $7 \mathrm{P}$ CSCL $1 O A$

N92-13482

Unclas 


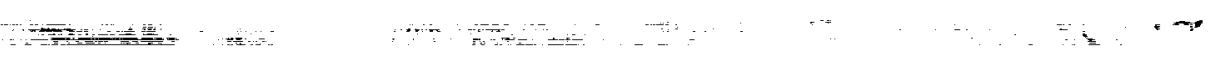

- - . . 


\section{A VERY LOW RESISTANCE, NON-SINTERED CONTACT SYSTEM FOR USE ON}

INDIUM PHOSPHIDE CONCENTRATOR/SHALLOW JUNCTION SOLAR CELLS

\author{
Victor G. Weizer \\ National Aeronautics and Space Administration \\ Lewis Research Center \\ Cleveland, Ohio 44135
}

Navid S. Fateıni

Sverdrup Teclinology. Inc.

Lewis Research Center Group

Brook Park, Olio 44142

\section{ABSTRACT}

An investigation is made into the possibility of providing low resistance contacts to shallow junction InP solar cells which do not require sintering and which do not cause device degradation even when subjected to extended annealing at elevated temperatures. We show that the addition of In to $\mathrm{Au}$ contacts in amounts that exceed the solid solubility limit lowers the as-fabricated (unsintered) contact resistivity $R_{c}$ to the $10^{-5}$ ohm $\mathrm{cm}^{2}$ range. If the In content is made to correspond exactly to that required to form the intermediate compound AugIn 4 , then the contacts so formed are stable, both electrically and metallurgically. even after extended annealing (12 hours) at $400 \mathrm{C}$. We next consider the contact system $\mathrm{Au} / \mathrm{Au}_{2} \mathrm{P}_{3}$ which has been shown to exhibit as-fabricated $R_{C}$ values in the $10^{-6}$ ohm $\mathrm{cm}^{2}$ range, but which fails quickly when heated. We show that the substitution of a refractory metal ( $W, T a$ ) for $A u$ preserves the low $R_{C}$ values while preventing the destructive reactions that would normally take place in this system at high temperatures. We show, finally, that $R_{c}$ values in the $10^{-7} \mathrm{ohm} \mathrm{cm}{ }^{2}$ range can be achieved without sintering by combining the effects of In or Ga additions to $A$ u contacts with the effects of introducing a thin $\mathrm{Au}_{2} \mathrm{P}_{3}$ layer at the metal-InP interface.

\section{INTRODUCTION}

The achievement of low resistance electrical contact to InP has, in the past, inevitably been accompanied by mechanical degradation of the InP itself. One method of achieving low contact resistance, for instance, is to create lattice disorder in the semiconductor via Ion etching and/or sputter deposition of the contact metallization. $(1-4)$ Depending on the severity of the damage to the InP lattice, the contacts so formed exhibit low resistance either as-fabricated or after mild heat treatment.

If lattice damage 18 not introduced prior to metal deposition, a sintering treatment at higher temperatures is necessary after deposition. Although a number of metal-semiconductor combinations have been tried, they all require heat treatments that result in the dissolution of substantial amounts of InP into the metallization in order to achieve low resistance values. $(4-10)$

For some applications the

dissolution of the semiconductor due to the sintering process and/or the damage resulting from ion etching can be tolerated. Devices such as the solar cell, however, where shallow junctions are the rule can be severely degraded if the damage to the semiconductor substrate is not precicely controlled.

While there are several remedial approaches to control the sinter-induced metallurgical interactions in shallow function devices, such as the use of rapid thermal annealing (RTA) techniques (4,9-1 between the semiconductor and the current carrying metallization $(12,13)$, their use adds complexity and an element of trial and error to the contacting process. A better solution would be to eliminate the need to sinter the contacts and thus avoid the device destroying metallurgical interactions that accompany the high temperature processing. The ideal solution would be to devise a contact system that exhibits low contact resistance as-fabricated, and which, in addition, would be able to withstand thermal stress, either intentional or unintentional, without destroying or degrading the device upon which it has been deposited.

In a previous publication we have described two methods of reducing the specific contact resistivity $R_{c}$ of as-fabricated Au based contacts to n-InP. $(14)$ We have shown that the addition of small amounts ( 1 ab) of $\mathrm{Ga}$ to Au contacts results in as-fabricated $R_{C}$ values in the high $10^{-5} \mathrm{ohm} \mathrm{cm}^{2}$ range. We have also shown that the insertion of a thin layer of $\mathrm{Au}_{2} \mathrm{P}_{3}$ at the interface between $A u$ and InP produces $R_{C}$ values in the high $10^{-6}$ to the low $10^{-5}$ ohm $\mathrm{cm}^{2}$ range. In both cases the $R_{C}$ reductions are observed in the as-fabricated state, without the need for sintering. Because the devices are not subfected to elevated temperatures there is negligible dissolution of InP into the metallization and thus no degradation of the electrical characteristics of the shallow $2000 \mathrm{~A} \mathrm{n} / \mathrm{p}$ Junction under the contacts. While the achievement of these low as-fabricated $R c$ values is a useful 
accomplishment, we find that both of the above approaches quickly fail when subjected to temperatures in the 300 to $400 \mathrm{C}$ range. Vigorous emitter destroying metal-Inp reactions are observed when devices with $\mathrm{Au} / \mathrm{Au}_{2} \mathrm{P}_{3}$ contacts are heated above $350 \mathrm{C}$ for a few minutes. With regard to the Au-Ga contact system, we find that while there is essentialiy no metallurgical interaction between InP and the Au-Ga metalizizacion even at elevated temperatures $(14)$, a few minutes at $400 \mathrm{C}$ is sufficient to cause a rise in Rc to values in the $10^{-3} \mathrm{ohm} \mathrm{cm}^{2}$ range.

Our purpose here is to describe the results of our efforts to preserve the low as-fabricated values of $R_{C}$ during extended heat treatment at elevated temperatures. We will also show that an additional order-of-magnitude decrease in the as-fabricated value of $R_{c}$ to the $10^{-7}$ ohm $\mathrm{cm}^{2}$ range can be achieved by combining the effect of $\mathrm{Ga}$ (Or $\mathrm{In}$ ) additions to $\mathrm{Au}$ contacts with that of inserting an $\mathrm{Au}_{2} \mathrm{P}_{3}$ layer at the metal-InP interface.

\section{EXPERIMENT}

The devices studied here were all $n / p$ diodes with epitaxially deposited emitters, $2000 \mathrm{~A}$ thick, Si doped to $1.7 \mathrm{X}$ $1018 \mathrm{~cm}^{-3}$. Substrate doping $(\mathrm{z} n)$ was $8 \mathrm{x}$ $1016 \mathrm{~cm}^{-3}$. Specific contact resistivity measurements were made using the transmission line method (TLM). We used electron beam evaporation to deposit the contact metallization. The samples were not actively cooled during evaporation. metal thickness of 2000 A was used throughout, unless otherwise stated. The Au/In alloy deposition technique is described elsewhere. (15) Ga was introduced into the metallization by sandwiching a $200 \mathrm{~A}$ Ga layer between two 900 A Au layers. The $\mathrm{Au}_{2} \mathrm{P}_{3}$ interlayer was formed by depositing a $40 \mathrm{~A}$ Au layer on the InP and anneafing it for a few minutes at 395 C. (14) The result is an array of $\mathrm{Au}_{2} \mathrm{P}_{3}$ is lands (approximately $0.5 \mathrm{micrometers}$ in diameter, several micrometers apart) under a thin layer of $\mathrm{Au}_{3} \mathrm{In}$. The contacts are subsequently built up by metal deposition after carefully redefining the TLM pattern photolithographically.

Sintering was performed in a rapid thermal annealing (RTA) apparatus that provides rise times of 10 seconds or less with negligible overshoot (forming gas ambient). To monitor the degree of emitter dissolution/perforation caused by the sintering process we observed the quality of the diode I-V characteristic. As a measure of the I-V quality we arbitrarily defined a diode conduction voltage $V_{l}$ as the voltage at which the forward current through the TLM patterned
diode (area $5.6 \times 10^{-3} \mathrm{~cm}^{2}$ ) is 1 mA $\{14\}^{2}$
A good pn junction should exhibit a $v_{1}$ of about $900 \mathrm{mV}$. Lower values of $\mathrm{v}_{1}$ indicate a degraded emitter.

Compositional analysis was performed via $x$-ray photoelectron spectroscopy (XPS). The XPS system was specifically calibrated for use with both the Au-In and the Au-Ga binary systems. (16)

\section{THE EFFECT OF Ga AND In ADDITIONS}

As illustrated in figure 1, the addition of small amounts of $\mathrm{Ga}$ to $\mathrm{Au}$ contacts results in a tenfold reduction in the specific contact resistance.(14) As Been in figure 2, however, the resistance gains are quickly lost if the temperature is raised briefly to the 300 to $400 \mathrm{C}$ range. (14) As well as reducing $R_{C}$, Ga additions have also been shown to drastically reduce the dissolution of InP into the metallization by inhibiting the interstitial entry of In into the $A u$ lattice. $(14)$ The suggested connection between these two effects (1.e., between the electrical effects and the metallurgical effects) is that Ga, in slowing the In entry rate, permits the dissipation of the $p$ atoms that are released at the Au-InP interface when In interstitially enters the metallization. The result is a decrease in the amount of accumulated $P$ at the interface and thus a reduction in $R_{c}$. (I4)

If this mechanism is correct, then other methods of reducing the in entry rate should also be effective in lowering $R_{c}$. One method of inhibiting In entry would be to purposely saturate the Au contact metalization with In. Since low temperature In entry (stage I) stops once the In concentration reaches the solid

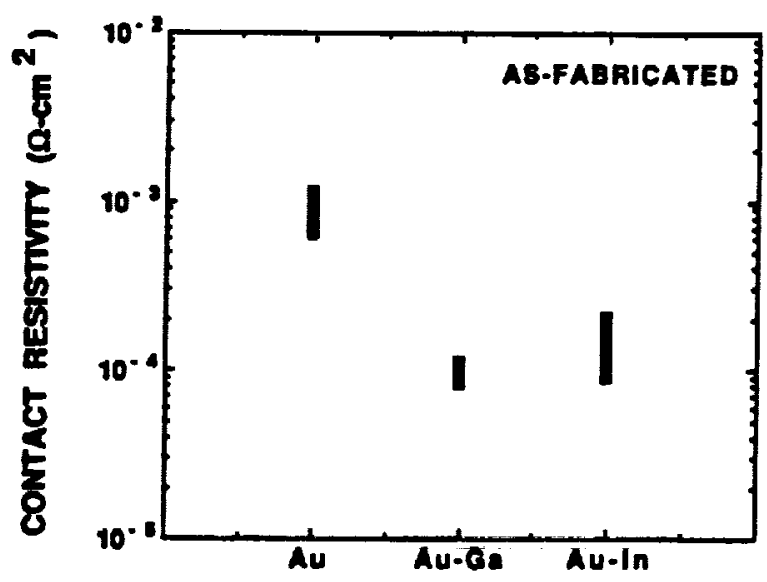

Figure 1. Measured as-fabricated contact resistivities for Au-only (8), Au-Ga (6), and Au-In (16) contacts on InP.

parentheses indicate number of samples. 
solubility limit(15), a saturated Au(In) solid solution contact system would preclude In entry, at least at low temperatures. With this in mind we fabricated a number of samples contacted with various Au-In mixtures. The In content in the contacts ranged from 12 to 35 as. When we measured the as-fabricated contact resistivities of these samples (figure 1) we found, as suspecter, an order of magnitude drop in $R_{C}$. This finding not only provides support for the suggested mechanism, but it also presents us with the opportunity to deposit a thermodynamically stable Au-In alloy which will not react with the Inp substrate when the temperature 1 s ralsed. AugIn 4 is thermodynamically stable with respect to InP. It has been shown to be the terminal compound that is formed in the series of solid state reactions that take place between Au and InP. (17) Figures 3 and 4 show the behavior of contacts composed of AugIn 4 and other Au-In mixtures during heat treatment at $400 \mathrm{C}$. As can be seen, the conduction voltage of the AugIn 4 contacted diode remains invariant even after 12 hours at temperature. The contacts with In content either greater than or less than the 30 or so needed to form AugIn 4 , on the other hand, can be seen to react with the InP, effectively destroying the underlying $n / p$ diodes.

In the case of the 23 In contacts, the In required to convert the metallization to AugIn 4 was obviously supplied by the dissolving InP emitter. If the In content is greater than that of AugIn 4 (i.e. the 35 a in sample), then higher In content alloys, such as AuIn2. apparently nucleate and grow, again

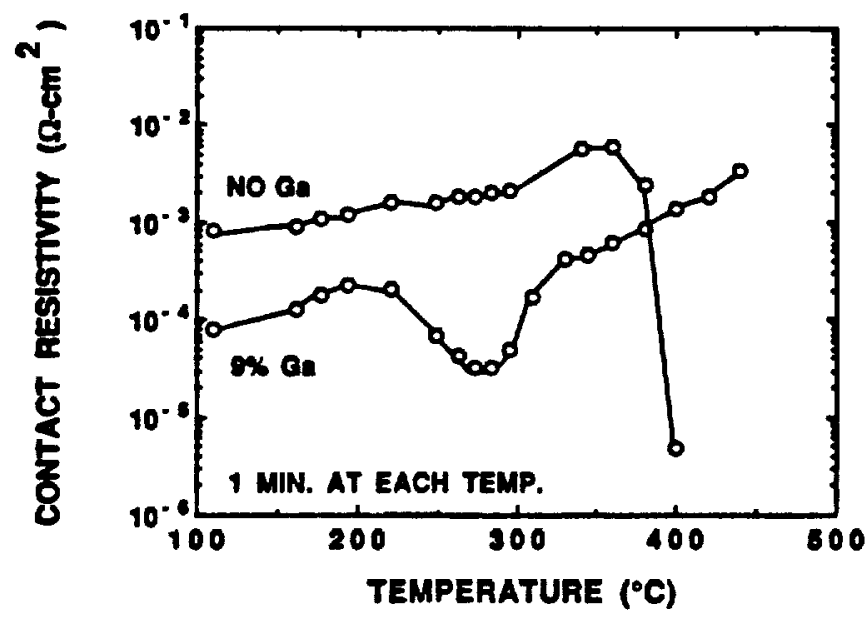

Figure 2. The effect of sintering on the specific contact resistivity of Au-only and $A u-9$ a $\mathrm{Ga}$ contacts on InP. requiring InP dissolution. Evidence for this is the fact that the metalidzation exhibits large pink areas after heat treatment, indicating that In is being leached from the silver colored AugIn 4 (leaving behind the pink colored Au $\mathrm{In}$ ) to form AuIn, or other high In content alloys. Since some of the In to form these alloys comes from the InP substrate, the integrity of the underlying emitter is degraded, as evidenced by the drop in $\mathrm{v}_{1}$. It should be noted, however, that the $3 \frac{1}{5}$ a In sample is stable for several hours at $400 \mathrm{C}$ while the higher In content phase is being nucleated. For this sample a nucleation time of two hours at $400 \mathrm{C}$ is Indicated by the initial invariance of $v_{1}$.

Thus, as-fabricated contact resistivities in the high $10^{-5} /$ low $10^{-4}$ ohm $\mathrm{cm}^{2}$ range that are not affected by extended heat treatment at $400 \mathrm{C}$ can be readily achieved through the use of the thermodynamically stable alloy AugIn 4 .

\section{THE EFFECT OF AN AU $2 P_{3}$ INTERIAYER}

As mentioned in the introduction, we have shown that as-fabricated $R_{c}$ values in the high $10^{-6}$ to the low $10^{-5} \mathrm{ohm} \mathrm{cm} \mathrm{cm}^{2}$ range can be achieved with $A u$ contacts by introducing a thin $\mathrm{Au}_{2} \mathrm{P}_{3}$ layer at the Au-InP interface (figure 5 ). (14) These contactB, however, cannot withstand exposure to elevated temperatures. The metallurgical interactions that take place in a few minutes at $350 \mathrm{C}$ are sufficient to destroy an underlying 2000 A thick emitter. In an attempt to avoid these device destroying reactions we sought to replace the reactive Au metallization with a more metallurgically inert refractory

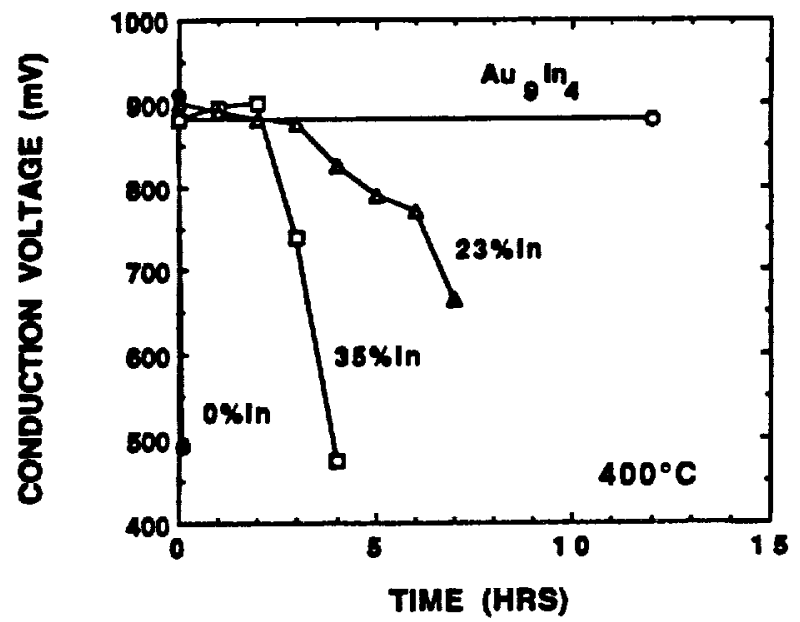

Figure 3 . The variation of conduction voltage with time at $400 \mathrm{C}$ for $\mathrm{Au}$ contacts containing various amounts of $\mathrm{In}$. 
metal. Thus, after depositing and annealing a $40 \mathrm{~A}$ Au layer to form an $\mathrm{Au}_{2} \mathrm{P}_{3} / \mathrm{Au}_{3}$ In interlayer, we built up the TLM contact pattern with a 2000 A layer of either W, Ta, or Mo.

As seen in figure 5 , the use of $a$. refractory metal instead of Au does not significantly affect the value of the as-fabricated contact resistivity. Values In the low $10^{-5}$ ohm $\mathrm{cm}^{2}$ range are easily achieved.

The next question was whether these contacts would react destructively with InP at elevated temperatures. The results of annealing $\mathrm{Ta} / \mathrm{Au}_{2} \mathrm{P}_{3}-$ and

$W / \mathrm{Au}_{2} \mathrm{P}_{3}$-contacted InP at $400 \mathrm{C}$ for a number of hours are shown in figures 6 and 7. respectively. In both cases the contact resistance remained low and there was effectively no metallurgical reaction with the InP substrate. Thus the substitution of $T a$ or $W$ for $A U$ in the $\mathrm{Au} / \mathrm{Au}_{2} \mathrm{P}_{3}$ system preserves the low as-fabricated $R_{c}$ values achieved with $\mathrm{Au} / \mathrm{Au}_{2} \mathrm{P}_{3}$, while at the same time preventing the high temperature InP-metal interactions that would otherwise destroy shallow Junction devices such as these.

\section{THE $\mathrm{Au}_{2} \mathrm{P}_{3}$ INTERLAYER WITH Ga-Au AND In-Au BUILDUP}

The $R_{c}$ reductions obtalned by adding $G a$ or In to Au contacts and the reductions effected by adding an $\mathrm{Au}_{2} \mathrm{P}_{3}$ interlayer are apparently additive. Figure 8 shows the as-fabricated $R_{c}$ values achieved by depositing either $A u-9$ a Ga or a Au-In mixture over a thin $\mathrm{Au}_{2} \mathrm{P}_{3}$ interlayer. As can be seen, $R_{c}$ values in the $10^{-7}$ ohm $\mathrm{cm}^{2}$ range have been achieved, again

as-fabricated, without the need for

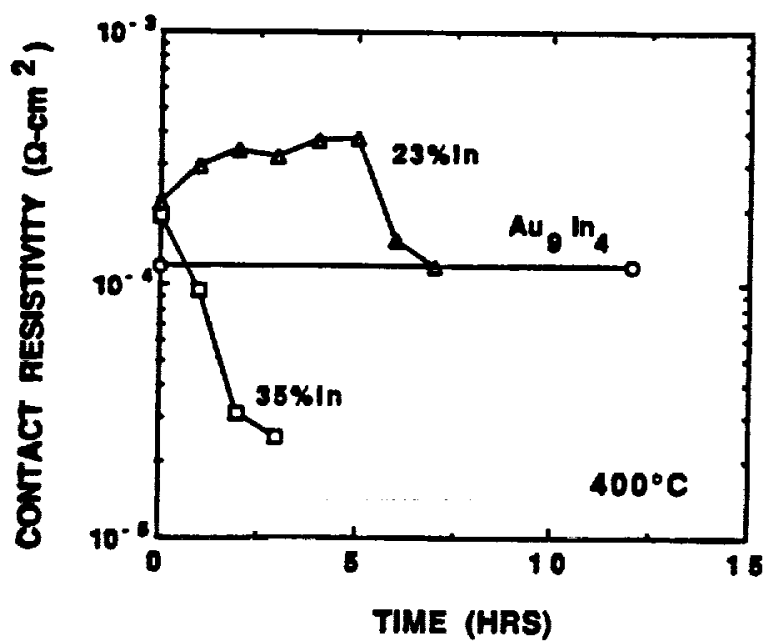

Figure 4. The variation of contact resistivity with time at $400 \mathrm{C}$ for $\mathrm{Au}$ contacts containing various amounts of $I n$. sintering. The additive nature of these two effects is not easily understood.

Some sort of synergistic mechanism must come into play to produce $R_{c}$ values significantly lower than either effect can produce by itself. The task of preserving these low $R_{C}$ values while preventing semiconductor dissolution as the temperature is increased appears to be made more difficult by the presence of the $\mathrm{Au}_{2} \mathrm{P}_{3}$ interlayer. Heat treatment of the $\mathrm{Au}-\mathrm{Ga} / \mathrm{Au}_{2} \mathrm{P}_{3}$ contact system at temperatures in the 300 to $400 \mathrm{C}$ range, for example, showed that although there was little or no metal-semiconductor intermixing (i.e... no change in $v_{1}$ ), the value of $R_{C}$ was very sensitive to temperature increases. The value of $R_{c}$ was observed to rise two orders of magnitude after only 10 minutes at $350 \mathrm{C}$ even though $\mathrm{V}_{1}$ remained unchanged.

Although one would expect $v_{1}$ to remain unchanged because of the reaction suppressing effects of $\mathrm{Ga}$ in the metallization(14), the abrupt increase in $R_{c}$ is somewhat of a surprise. With the suspicion that something had happened at the $\mathrm{Au}_{2} \mathrm{P}_{3}$-InP interface, we removed the metallization from two samples, one which had been heat treated and one which had This etchant readily removes all Au-based metal alloys but does not remove $\mathrm{Au}_{2} \mathrm{P}_{3}$. Upon microscopic examination of the stripped samples we found $\mathrm{Au}_{2} \mathrm{P}_{3}$ on the InP surface of the unheated sample (as expected), but not on the heated (high resistance) sample.

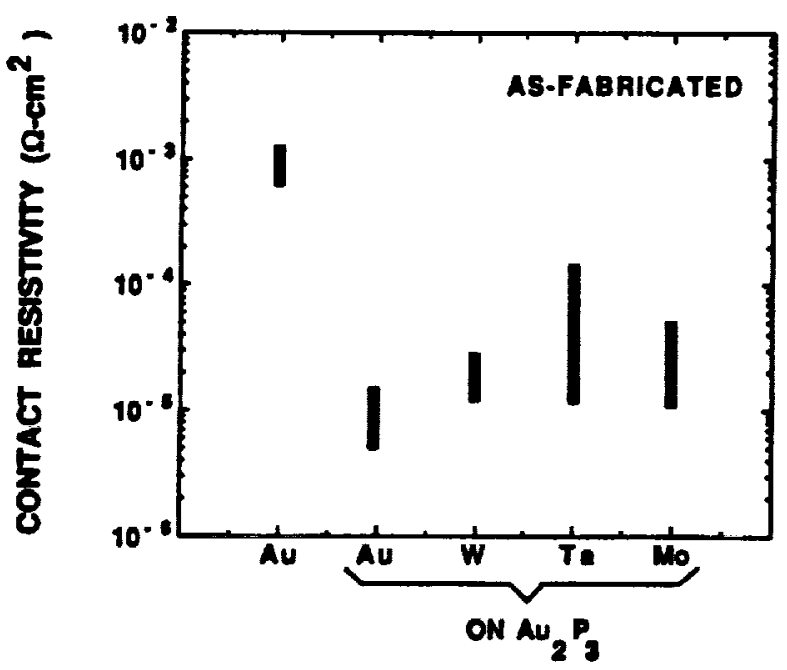

Figure 5. Measured as-fabricated contact resistivities for Au-only and for Au $(10), W(6), T a(7)$, and Mo (2) on a thin $\mathrm{Au}_{2} \mathrm{P}_{3}$ interlayer. Parentheses indicate number of samples. 
It is felt that the $\mathrm{Au}_{2} \mathrm{P}_{3}$ in the heated samples may have been physically separated from the InP by the accumulation of vacancies that are generated as In (from InP) enters the metallization interstitially when the sample is heated. If Ga were not present in the metallization, the vacancies generated at the interface would be annihilated by capturing interstitial Au atoms formed during the Au-to-AuzIn phase transition (stage II).(17) The result would be the formation of additional $\mathrm{Au}_{2} \mathrm{P}_{3}$ at the $\mathrm{Au}_{2} \mathrm{P}_{3}$-InP interface.(17) However, Bince the presence of $G a$ has been shown to prevent Au interstitial formation(14), the vacancies, rather than being annihilated, accumulate at the InP-Au ${ }_{2} \mathrm{P}_{3}$ interface where they eventually cause a physical separation. It appears, therefore, that unless vacancy accumulation can be prevented, one must avoid post-fabrication heat treatment of the otherwise thermally stable Au-Ga/Au ${ }_{2} P_{3}$ contact system. In our investigation of the thermal stability of the Au-In/Au $2 \mathrm{P}_{3}$ contact system we concentrated on the 30 as In alloy Augin 4 since it had proved to be non-reactive when deposited alone on InP. When we annealed $A u_{9} I n_{4} / A_{2} P_{3}$ contacted diodes in the 300 to $400 \mathrm{C}$ range we found that the $R_{C}$ values remained essentially unchanged.

In contrast to the AugIn 4 -only

contacts, however, the AugIn $4 / \mathrm{Au}_{2} \mathrm{P}_{3}$

contacts reacted metallurgically with

InP. As seen in figure 9 , at $400 \mathrm{C} \mathrm{V}$ drops monotonically with time until after 4 hours the underlying pn junction has an I-V characteristic of a schottky diode. All is apparently not lost for these contacts, however, since we found that if

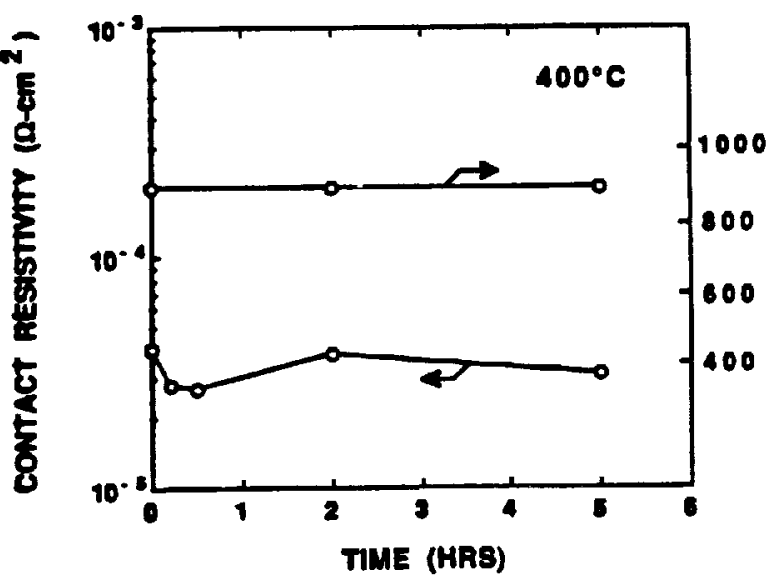

Figure 6 . The variation of contact resistivity and conduction voltage with time at $400 \mathrm{C}$ for $\mathrm{Ta}_{\mathrm{Au}} \mathrm{P}_{3}$ contacts on InP. we lower the temperature 50 degrees to the $350 \mathrm{C}$ range, the contacts show no sign of deterioration after 7 hours in the sintering furnace.

While the mechanisms involved are not clear at the present, the presence of the $\mathrm{Au}_{2} \mathrm{P}_{3}$ interlayer apparently promotes the metallurgical interaction of InP with both of these otherwise stable contact metallizations. Care must therefore be taken to see that post fabrication heat treatments are kept within the allowable limits.

\section{SUMMĀRY}

We have investigated the possibility of providing low as-fabricated resistance contacts to InP which are able to withstand extended thermal stress at elevated temperatures. Our major findings are as follows:

1) We have found that In additions to Au contact metallization result in as-fabricated contact resistivity values in the high $10^{-5} \mathrm{ohm} \mathrm{cm}^{2}$ range.

2) If the amount of In added corresponds to that required to form AugIn $(30$ a 8$)$, then the contacts so formed are not affected by extended heat treatment at $400 \mathrm{C}$.

3) Although the $\mathrm{Au} / \mathrm{Au}_{2} \mathrm{P}_{3}$ contact system provides as-fabricated contact resistivity values in the $10^{-6} \mathrm{ohm} \mathrm{cm}^{2}$ range, the contacts are not stable when heated. The substitution of a refractory metal ( $W, T a, M o)$ for Au in this system preserves the low as-fabricated $R_{c}$ values achieved with Au/Au ${ }_{2} \mathrm{P}_{3}$ while at the same time preventing the high temperature InP-metal interaction that would otherwise destroy ahallow junction device.

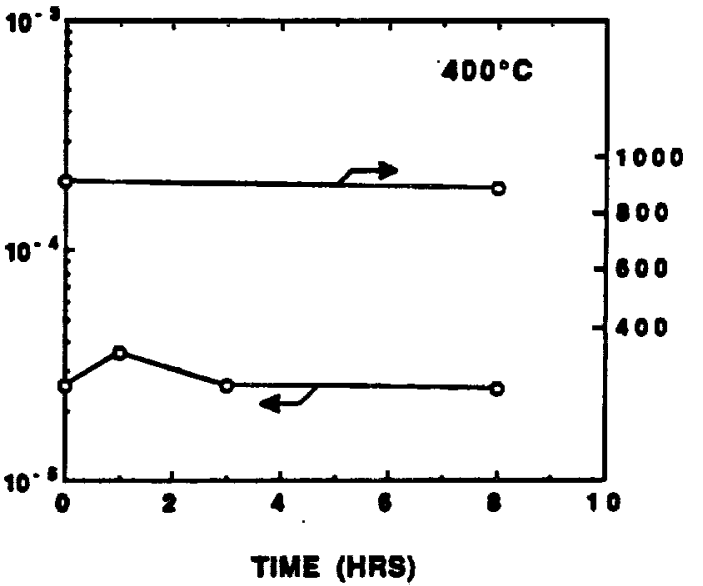

Figure 7 . The variation of contact resistivity and conduction voltage with time at $400 \mathrm{C}$ for $\mathrm{W} / \mathrm{Au}_{2} \mathrm{P}_{3}$ contacts on InP. 
4) The $R_{c}$ reductions achieved by adding $G a$ or In to $A u$ contacts and the reductions effected by introducing an $\mathrm{Au}_{2} \mathrm{P}_{3}$ interlayer are apparently additive. As-fabricated $R_{c}$ values in the $10^{-7}$ ohm $\mathrm{cm}^{2}$ range can be achieved by depositing either Au-9 a Ga or a Au-In mixture over a thin $\mathrm{Au}_{2} \mathrm{P}_{3}$ interlayer.

5) AugIn $4 / \mathrm{Au}_{2} P_{3}$ contacts with $R_{C}$ values in the high $10^{-7}$ to low $10^{-6} \mathrm{ohm}$ $\mathrm{cm}^{2}$ range, as-fabricated, withstand heat treatment at $350 \mathrm{C}$ for at least 7 hours without degrading. Metallurgical interaction is observed during sintering at $400 \mathrm{C}$, however, which results in substantial damage to the underlying device.

6) While there is essentially no metallurgical interaction between InP and the Au-9 a $\mathrm{Ga} / \mathrm{Au}_{2} \mathrm{P}_{3}$ contact system during heat treatment at $400 \mathrm{C}$, vacancy accumulation at the InP-Au $\mathrm{P}_{3}$ interface causes a physical separation of the $\mathrm{Au}_{2} \mathrm{P}_{3}$ interlayer from the InP with the result that the low as-fabricated values of $R_{c}$ are quickly lost.

\section{REFERENCES}

1) W.C.Dautremont-Smith, P.A.Barnes, and J.W.Stayt, J. Vac. Sci. Technol. B2, 620 (1984).

2) R.Raumans, N.Grote, H-G.Bach, and F.Fidorra, Inst. Phys. Conf. Ser. 91, 501 (1987).

3) A.Katz, w.C.Dautremont-Smith, S.N.G.Chu, S.J.Pearton, M.Geva, B.E.Weir, P.M.Thomas, and L.C.Kimerling, Mat. Res. Soc. Symp. Proc. 181, 401 (1990).

4) A.Applebaum, M.Robbins, and F. Schrey,

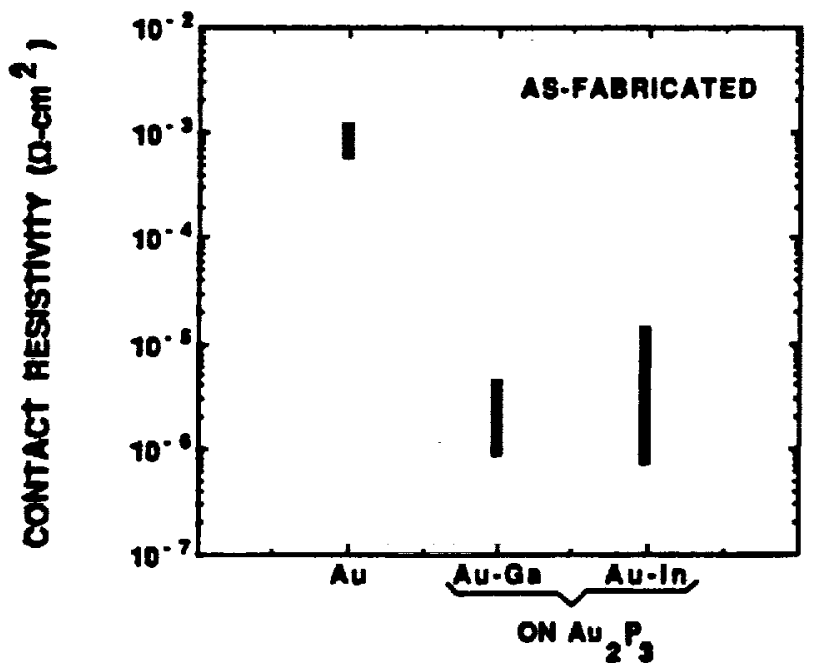

Fiqure 8 . Measured as-fabricated contact resistivities for Au-only and for Au-9 as $\mathrm{Ga}(4)$ and various Au-In mixtures (10) on $\mathrm{Au}_{2} \mathrm{P}_{3}$ interlayer. Parentheses indicate number of samples.
IEEE Trans. Electron Devices ED-34, 1026 (1987).

5) K.P.Pande, E.Martin, D.Gutierrez, and O.Aina, Solid-st. Electron. 30, 253

(1987).

6) L.P.Erickson, A.Waseem, and

G.Y.Robinson, Thin Solid Films 64, 421

(1979).

7) J.A.del Alamo and $T$ Mizutani. Solid-st. Electron. 31, 1635 (1988).

8) M.F.J.O'Reefe, R.E.Miles, and M.J.Howes, Proc. Indium Phosphide and Related Materials, SPIE 1144, 361 (1989). 9) A.Ratz, B.E.Weir, S.N.G.Chu,

P.M.Thomas, M.Soler, T.Boone, and

W.C.Dautremont-Smith, J. Appl. Phys. 67, $3872(1990)$.

10) P.A.Barnes and R.S.Williams,

Solid-St. Electron. 24, 907 (1981).

11) G.Bahir and T.W.SIgmon, J. Electron. Mater. 16, 257 (1987).

12) B.K.Liew, J.L.Tandon, and

M.A.Nicolet, Solid St. Electron. 30, 571 (1987).

13) J.J.Berenz, G.J.Scilla, V.L.Wrick, L.F.Eastman, and G.H.Morrison, J. Vac. Sci. Technol. 13, 1152 (1976).

14) V.G.Weizer and N.S.Fatemi, J. Appl. Phys. 69, 8253 (1991).

15) N.S.Fatemi and V.G.Weizer, J. Appl. Phys. 67, $1934(1990)$.

16) D.T.Jayne, N.S.Fatemi, and

V.G.Weizer, Proc. 37th American Vacuum

Soc. Symp., Toronto, 1990; NASA TM 103659. 17) V.G.Weizer and N.S.Fatemi, J. Appl. Phys. 68, 2275 (1990).

18) N.S.Fatemi and V.G.Weizer, J. Appl. Phys. 65, 2111 (1989).

* Under contract NAS3-25266 with the NASA Lewis Research Center.

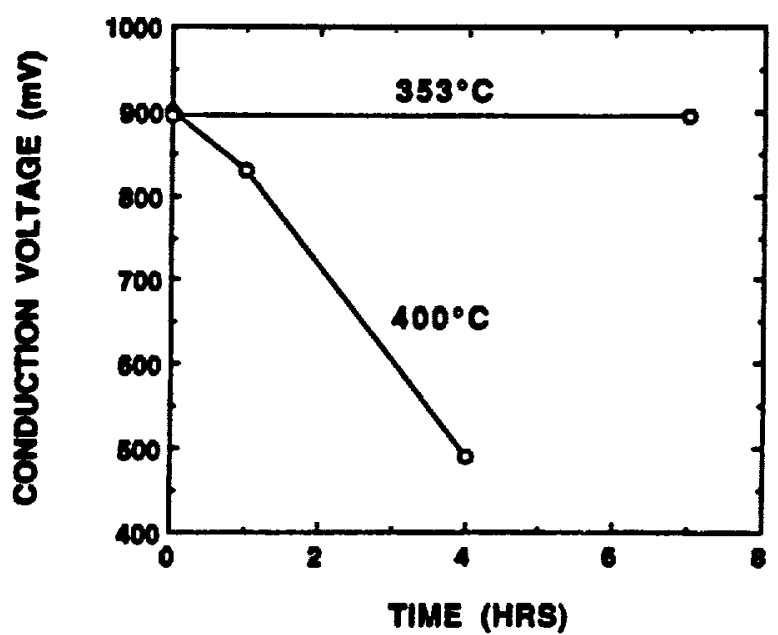

Figure 9. The variation of conduction voltage with time for $\mathrm{Au}_{9} \mathrm{In}_{4} / \mathrm{Au}_{2} \mathrm{P}_{3}$ contacts on InP. 
Public reporting burden for this collection of information ls estimated to average 1 hour per response, including the time lor revlewing insiructions, searching existing dala sources, gathering and maintalning the data needed, and completing and revlewing the collection of information. Send comments regarding this burden estimate or any other aspect of this collection of information, including suggestions for reducing this burden, to Washinglon Headquarters Services, Direclorate for information Operations and Reports, 1215 Jellerson Davis Highway, Suite 1204, Arlington, VA 22202-4302, and to the Office of Managernent and Budget, Paperwork Reduction Project (0704-0188), Washington, DC 20503.

1. AGENCY USE ONLY (Leave blank)

4. TITLE AND SUBTITLE 2. REPORT DATE

October 1991

\section{REPORT TYPE AND DATES COVERED}

Technical Memorandum

A Very Low Resistance, Non-Sintered Contact System for Use on Indium

Phosphide Concentrator/Shallow Junction Solar Cells

\section{AUTHOR(S)}

WU-506-41-11

Victor G. Weizer and Navid S. Fatemi

\section{PERFORMING ORGANIZATION NAME(S) AND ADDRESS(ES)}

National Aeronautics and Space Administration

Lewis Research Center

Cleveland, Ohio 44135-3191

8. PERFORMING ORGANIZATION REPORT NUMBER

E-6604

9. SPONSORING/MONITORING AGENCY NAMES(S) AND ADDRESS(ES)

10. SPONSORING/MONITORING AGENCY REPORT NUMBER

National Aeronautics and Space Administration

Washington, D.C. 20546-0001

NASA TM -105279

\section{SUPPLEMENTARY NOTES}

Prepared for the 22nd Photovoltaic Specialists Conference sponsored by the Institute of Electrical and Electronics Engineers, Las Vegas, Nevada, October 7-11, 1991. Victor G. Weizer, NASA Lewis Research Center; Navid S. Fatemi, Sverdrup Technology, Inc., 2001 Aerospace Parkway, Brook Park, Ohio 44142. Responsible person, Victor G. Weizer, (216) 433-2230.

12.. DISTRIBUTION/AVAILABILITY STATEMENT 12b. DISTRIBUTION CODE

Unclassified - Unlimited

Subject Category 44

13. ABSTRACT (Max/mum 200 words)

An investigation is made into the possibility of providing low resistance contacts to shallow junction InP solar cells which do not require sintering and which do not cause device degradation even when subjected to extended annealing at elevated temperatures. We show that the addition of In to Au contacts in amounts that exceed the solid solubility limit lowers the as-fabricated (unsintered) contact resistivity $R_{c}$ to the $10^{-5} \mathrm{ohm} \mathrm{cm}^{2}$ range. If the In content is made to correspond exactly to that required to form the intermediate compound $\mathrm{Au}_{9} \mathrm{In}_{4}$, then the contacts so formed are stable, both electrically and metallurgically, even after extended annealing ( 12 hours) at $400^{\circ} \mathrm{C}$. We next consider the contact system $A u / A_{2} P_{3}$ which has been shown to exhibit as-fabricated $R_{c}$ values in the $10^{-6} \mathrm{ohm} \mathrm{cm}{ }^{2}$ range, but which fails quickly when heated. We show that the substitution of a refractory metal (W, Ta) for Au preserves the low $R_{c}$ values while preventing the destructive reactions that would normally take place in this system at high temperatures. We show, finally, that $R_{c}$ values in the $10^{-7} \mathrm{ohm} \mathrm{cm}^{2}$ range can be achieved without sintering by combining the effects of In or $\mathrm{Ga}$ additions to Au contacts with the effects of introducing a thin $\mathrm{Au}_{2} \mathrm{P}_{3}$ layer at the metal-InP interface.

\begin{tabular}{|c|c|c|}
\hline \multicolumn{3}{|c|}{$\begin{array}{l}\text { 14. SUBJECT TERMS } \\
\text { Indium phosphide; Contacts }\end{array}$} \\
\hline $\begin{array}{l}\text { 17. SECURITY CLASSIFICATION } \\
\text { OF REPORT } \\
\text { Unclassified }\end{array}$ & $\begin{array}{l}\text { 18. SECURITY CLASSIFICATION } \\
\text { OF THIS PAGE } \\
\text { Unclassified }\end{array}$ & $\begin{array}{l}\text { 19. SECURTY CLASSIFICATION } \\
\text { OF ABSTRACT } \\
\text { Unclassified }\end{array}$ \\
\hline
\end{tabular}


